\title{
¿SE ORIGINA LA FALACIA EN HUME?
}

\author{
Luis Manuel Sánchez Fernández \\ Universidad Nacional de San Agustín, Arequipa, Perú
}

RESUMEN. Este artículo está dirigido a interpretar el sentido de las afirmaciones de Hume sobre la relación entre proposiciones de ser y deber ser, en comparación con las implicancias de la llamada falacia naturalista postulada por G. E. Moore. El análisis revela que las teorías de ambos autores se hallan muy distantes la una de la otra. Más aún, de aceptarse la tesis de Moore, la primera en ser afectada vendría a ser la teoría de los sentimientos morales de Hume. Sobre esta base, el artículo sugiere que tanto la ley de Hume como la tesis de la falacia no son de por sí una valla invencible para algún tipo de naturalismo normativo.

Palabras clave: Hume, G. E. Moore, falacia naturalista.

ABSTRACT. This essay's purpose is to interpret Hume's theory on «iS» and "ought», in comparison with the G. E. Moore's thesis of naturalistic fallacy. The analysis reveals that these theories are far distant to each other; moreover if Moore's thesis is accepted, Hume's theory of moral sentiments would not make any sense. On these grounds the essay puts forward the central idea that neither hume's law nor naturalistic fallacy, are invincible obstacles against some ethical naturalism by themselves.

Keywords: Hume, G. E. Moore, naturalistic fallacy. 


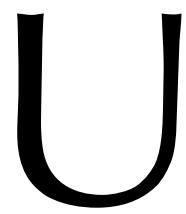

n famoso párrafo de Hume en la página 521 de $A$ Treatise on Human Nature (1739), de apariencia casual y algo distante del texto que le antecede - suscita desde entonces numerosas discusiones, respecto a la posibilidad de los juicios morales-. El debate fue planteado en especial a comienzos del siglo XX, con énfasis entre los filósofos, sin que deje de tener implicancias para los juicios legales, políticos y en general para todas las enunciaciones lingüísticas de contenido evaluativo y práctico. El citado parágrafo —para recordarlo una vez más- es el siguiente:

No puedo evitar añadir a estos razonamientos una observación que quizás puede tener alguna importancia. En cada sistema de moralidad que he observado hasta ahora, encuentro siempre que el autor procede algunas veces en la forma ordinaria de razonamiento, y establece la existencia de Dios, o hace observaciones sobre asuntos humanos, cuando de repente soy sorprendido porque, en vez de las usuales copulaciones de proposiciones «es» o «no es», me encuentro con proposiciones ninguna de las cuales no está conectada con un «debe» $\mathrm{o}$ «no debe». Este cambio es imperceptible, pero es sin embargo de consecuencias últimas; porque como este «debe», o «no debe», expresa alguna nueva relación o afirmación, ésta debe necesariamente observarse y explicarse; al mismo tiempo debe darse una razón para algo que parece completamente inconcebible: cómo esta nueva relación puede ser una deducción de otras que son completamente diferentes de ella. Pero como los autores no toman comúnmente esta precaución, debo intentar recomendarla a los lectores; y estoy persuadido que esta pequeña atención subvertiría todos los sistemas vulgares de moralidad; y permite ver que la distinción de vicio y virtud no se encuentra simplemente en las relaciones entre objetos, ni es percibida por la razón ${ }^{1}$.

La interpretación estándar de este texto, de acuerdo con la importante selección ofrecida por HUDSON en 1969, sostiene que HuME estaría afirmando aquí la existencia de una barrera lógica (gap) —o una «guillotina», como escribiría Max BLACK en 1964entre proposiciones de es y proposiciones de debe ser, sea porque el debe no puede ser reducido a es, o porque el debe tampoco puede ser lógicamente derivado de aquél ${ }^{2}$. En otro texto HUDSON señala, además, que al decir de los partidarios de la interpretación estándar, el reconocimiento de esta valla se hallaría en la base de filosofías como las de MOORE, STEVENSON o HARE ${ }^{3}$.

A partir del párrafo ciertos autores proyectan dos conclusiones adicionales:

${ }^{1}$ El texto de la versión original es el siguiente: «I cannot forbear adding to these reasoning an observation, which may, perhaps, be found of some importance. In every system of morality, which I have hitherto met with, I have always remark'd, that the author proceeds for some time in the ordinary way of reasoning, and establishes the being of God. Or makes observations concerning human affairs; when of a sudden I am surpriz'd to find, that instead of the usual copulations of propositions, is, and is not, I meet with no proposition that is not connected with and ought, or an ought not. This Change is imperceptible; but is, however, of the last consequence. For as this ought, or ought not, expresses some new relation or affirmation, "tis necessary that it shoul'd be observ'd and explain'd; and at the same time that a reason should be given, for what seems altogether inconceivable, how this new relation can be a deduction from others, which are entirely different from it. Bus as authors do not commonly use this precaution, I shall presume to recommend it to the readers; and am persuaded, that this small attention wou'd subvert all the vulgar systems of morality, and let us see, that the distinction of vice and virtue is not founded merely on the relations of objects, nor is perceiv'd by reason”». D. HuME, 1985 [1739-1740]. A Treatise of Human Nature, Penguin Books: 521, Traducción libre del autor. Lo mismo para todas las traducciones que siguen.

2 Hudson, 1969: The Is-Ought Question, MacMillan, p. 13.

3 Hudson, 1985 [1970]: Modern Moral Philosopby, MacMillan, p. 254.

4 Idem. 
a) Que para HumE ninguna otra derivación es posible, desde que para el autor inglés todo razonamiento sería deductivo o defectuoso ${ }^{4}$.

b) Que, además, cualquier posibilidad de fundar la moralidad en hechos vendría condenada por el citado texto, llamado a veces como la «ley de HuME».

Debería decirse que en particular este segundo enunciado es casi un lugar común en la literatura corriente sobre el tema. En un reciente texto Gerhard SCHURZ sostiene, por ejemplo, que si la tesis de HumE es cierta, entonces no es posible derivar derechos — como el «derecho a la vida»- a partir de hechos empíricos 5 .

Mientras la interpretación estándar tiene pocos adversarios, estos dos últimos supuestos no gozan, sin embargo, del mismo respaldo. Geoffrey HuNTER, por ejemplo, cree que aunque puede aceptarse la existencia del gap deductivo, e incluso compartir la creencia de que los argumentos o son deductivos o son defectuosos; subsiste sin embargo en la teoría de HuME, la identificación de los juicios morales con afirmaciones de hecho, o su equivalencia lógica con ciertas proposiciones de «es» ${ }^{6}$, HUNTER entiende que eso es posible porque en el párrafo HuME no dice que la derivación sea «inconcebible», sino que «parece» inconcebible, dando a entender que esperaría que ello pueda ser aclarado. MACINTYRE, por su lado entiende que el gap deductivo es asumible pero no el dilema «deductivo o defectuoso», de tal modo que aunque HumE excluye la posibilidad de inferir un debe de un $e s^{7}$, no descarta la posibilidad de mantener la conexión ser-deber ser a través de un mecanismo de razonamiento análogo, por ejemplo, al de la inducción ${ }^{8}$.

La asunción de la hipótesis b) resulta especialmente precaria, porque entonces no se entiende el naturalismo de la teoría moral de HumE; y porque además, las posibilidades de una fundamentación naturalista de las afirmaciones morales parecen ser indiferentes a las consecuencias de la «guillotina», cualesquiera sean estas, como ha sido sostenido recientemente por PIGDEN ${ }^{9}$ y tendremos ocasión de tratar más adelante.

En este ensayo, escrito desde las expectativas del Derecho y la ciencia política -y no desde la ética ni la lógica - añadiremos algunas razones más, en la dirección de HuNTER, MACINTYRE y PigDEN, para sostener la verosímil trivialidad ${ }^{10}$ del debate ser y deber ser y su inocuidad para frustrar las posibilidades de fundar la moral $-\mathrm{y}$ las proposiciones normativas de diferente tipo- en algún tipo de hechos. En esa dirección, el título del artículo es intencionadamente ambiguo en tres sentidos. Primero porque se propone indagar si la denominada «falacia naturalista» existe y si su señalamiento originario se halla en HUME; segundo, si en el supuesto de la existencia de la falacia no cabría la posibilidad de que la propia teoría moral de HumE hubiese incurrido en ella; tercero, si cuando se postula la «falacia naturalista» no se esta incurriendo más bien, subrepticiamente, en una falacia distinta —una más bien de carácter idealista— al su-

\footnotetext{
${ }^{5}$ Véase, Schurz, 1997: The Is-Ought Problem, Kluwer Academic Publishers, p. 3.

${ }^{6}$ HunTER: Hume on Is and Ought, en Hudson, 1969: 60.

${ }^{7}$ Hay que anotar que la posibilidad del paso deductivo de enunciados es a enunciados debe, tampoco se descarta por completo, por ejemplo en autores como BLACK y SEARLE. Ver HUdSON, 1969: 21-26.

${ }^{8}$ MACINTYRE: «Hume on "Is" and "Ought"», en The Philosophical Review, 1959, vol. 68, n. ${ }^{\circ} 4$ (octubre), pp. 452, 454-455. Cfr. también HUDSON, 1985: 259-260.

9 Pigden, Naturalism, en Singer, 1997 [1991]: A Companion to Ethics, Blackwell: pp. 421-431.

${ }^{10}$ SINGER, 1973: «The Triviality of the Debate Over "Is-Ought" and the Definition of "Moral"», American Philosophical Quarterly, X, 1, January.
} 
poner que a partir de imposibilidades lógico-formales se puede pasar a sostener, por fuerza de necesidad, imposibilidades reales: a saber la imposibilidad de que los hechos naturales cuenten para algún tipo de fundamentación moral, arrastrando en este imprevisto camino a HUME. Las tres rutas serán exploradas en lo que sigue.

\section{INTERPRETANDO A HUME}

Sin duda que las afirmaciones de HumE en el párrafo citado pueden comprenderse mejor si se toman en cuenta algunos de los otros argumentos que el autor expone en el libro III (Of Morals) del Treatise. Prosiguiendo con su filosofía general del conocimiento HumE mantiene que todo lo que está presente en la mente humana son percepciones ${ }^{11}$, las cuales pueden ser «expresiones» $\mathrm{o}$ «ideas». El autor no es expreso en decirlo, pero no es arbitrario entender de él que las primeras (las impresiones) se vinculan a las pasiones y las segundas (las ideas) a la razón. Además, como afirma en otro lado, las pasiones, voliciones y acciones no son susceptibles de verdad o falsedad, por lo que no puede saberse si son contrarias o conforme a la razón (510). A continuación añade que la moralidad no es demostrable, partiendo de suponer que las operaciones demostrativas del entendimiento humano son dos: comparación e inferencia de hechos, (515), las cuales son posibles por la existencia de relaciones entre objetos ${ }^{12}$. Pero virtud y vicio no son relaciones entre objetos, lo que significa que la moralidad no responde a tales relaciones, atribuibles sólo a la materia, a las acciones, pasiones y voliciones (515). Por tanto la moralidad no puede demostrarse (516).

$\mathrm{El}$ argumento demostrativo descubre relaciones entre objetos que en el caso de la moralidad no existen. La moralidad no consiste ni en relaciones ni en hechos; el vicio no se encuentra en ningún lado hasta que uno reflexiona internamente y «encuentra un sentimiento de desaprobación» (520). Por lo tanto, a diferencia de la razón, el vicio y la virtud no se descubren «simplemente» por comparación de ideas, sino por impresiones o sentimientos (522). De allí surge que no sólo las valoraciones morales de vicio o virtud, sino también los sentimientos que le sirven de base, no serían susceptibles de demostración.

Por otro lado, HumE mantiene que tampoco sería suficiente con mostrar que la moralidad es una «relación» (lo cual, se dijo, no cree posible), sino que es necesario mostrar cómo ella influye en la voluntad del hombre: «Una cosa es conocer la virtud y otra conformar la voluntad a ella. No es suficiente mostrar las relaciones sobre las cuales se funda» ${ }^{13}$. Su punto de vista es que la razón no tiene influencia en la morali-

${ }^{11}$ Hume, 1985: 508, 739-740. Por razones de facilidad en los párrafos siguientes las referencias a los textos de Hume se colocan entre paréntesis en el texto principal, salvo cuando se indique de otro modo.

${ }^{12}$ Hume postula que todas esas relaciones se subsumen en: similitud, contrariedad, grados de calidad, proporciones en cantidad y número, 1985: 515.

13 «Tis one thing to know virtud, and another to conform the will to it'tis not sufficient to show the relations upon which they (vice and virtud) are founded...» HuME, 1985: 517.

${ }_{14}$ Sin embargo Hume mantendrá que la influencia sería sólo en forma indirecta (511), la razón puede causar u orientar las pasiones pero no puede calificar las acciones como virtud o como vicio (514). Más adelante, en sus Enquiries de 1777, HumE sigue un razonamiento semejante, pero es de notar que la razón cobra algo más de valor en su argumentación: «I am apt to suspect... that reason and sentiment concur in almost all moral deter- 
dad, porque la moralidad es activa y la razón es pasiva (509). La razón es inerte y no tiene influencia en las afecciones ${ }^{14}$, como sí puede hacerlo la moralidad; por lo tanto, además de no ser demostrable, la moral tampoco puede ser derivada de la razón (509). La esterilidad de la razón para influir en la voluntad es postulada, además, en el contexto de su escepticismo respecto a la causalidad y su llamado empirismo según el cual las conexiones entre objetos del mundo no pueden ser extendidas más allá de la experiencia (517-518).

Siguiendo este razonamiento HumE concluye en que los filósofos no pueden probar ninguna de estas dos «condiciones»: ni que la moralidad se basa en «relaciones», ni que estas «relaciones», en el caso de existir, puedan ser universalmente obligatorias para la voluntad (518). Si la moralidad existiese como relación, piensa, incluso los animales deberían practicarla, al margen de que tengan o no conciencia de ella (519-520). «Este razonamiento — dice- no sólo prueba que la moralidad no consiste en relaciones, que son objeto de la ciencia; sino que si se examina probará con igual certeza que no consiste en algún asunto de hechos que pueda ser descubierto por el entendimiento» ${ }^{15}$ (520). Luego, en la página siguiente, inserta su conocido parágrafo trascrito al comienzo, en el cual dice hacer «una observación» que en realidad consiste en dos afirmaciones básicas: a) que los filósofos hablan corrientemente de proposiciones es (referidas a Dios por ejemplo) pero luego de súbito se pasan a hablar de proposiciones de deber ser, como si estas «relaciones» (de deber ser) tuvieran existencia, lo cual necesita explicarse; $b$ ) debe también explicarse el hecho «inconcebible» de cómo las nuevas «relaciones» (de deber ser) pueden ser una deducción de otras que son completamente diferentes (es) (521). Para efectos de este escrito llamaremos en adelante a este último enunciado la regla de la no derivabilidad deductiva, o formal, del debe a partir del es.

Se observa de inmediato una aparente equivalencia entre las dos «condiciones» que exige en la página 518 y las dos «observaciones» que hace en la página 521. En ambos casos Hume habla de «relaciones» y de cómo estas se vinculan entre sí; sin embargo, en el primero se refiere al problema de si las «relaciones» «pueden ser universalmente obligatorias para la voluntad» (lo cual parece más bien un problema sicológico o de causación); en tanto en el segundo HumE se ocupa expresamente de la posible deducibilidad que existiría entre ellas (el cual es más bien un problema lógico). Se podría decir que en el primer supuesto se mueve en el plano óntico (de los orígenes y efectos de la voluntad en la moral), en tanto en el segundo se mueve en un plano lógico (de los procesos del razonamiento moral). El giro es sutil pero no tanto como para no advertir que si la regla de no derivabilidad deductiva de la página 521 se extiende a las «condiciones» de la página 518, y se plantea como negación del vínculo de la moral con algún tipo de «relaciones»; se convierte enseguida en una tesis de incomunicabilidad absoluta entre ser y deber ser. No sólo que las afirmaciones morales no pueden derivarse deductivamente de afirmaciones sobre el ser, sino que la moral no tendría vínculo con existencia

minations and conclusions» (172), pero «it is probable, I say that this final sentence depends on some internal sense or feeling, which nature has made universal in the whole species». Hume, 1978 [1777]: Enquiries Concerning Human Understanding and Concerning the Principles of Morals, Oxford: Clarendon Press, p. 173.

${ }_{15}$ «Nor does this reasoning only prove, that morality consists not in any relations, that are the objects of science; but if examin'd, will prove with equal certainty, that it consists not in any matter of fact, which can be discover'd by the understanding». HuME, 1985: 520. 
alguna ¿Es esto lo que HumE quiere afirmar? Como veremos, esto no surge fehacientemente de ambos textos, menos aún del segundo.

El texto de la página 518 parece más dirigido a advertir la dificultad —sino imposibilidad - que habría para probar el vínculo entre lo que llama relaciones y las distinciones entre lo bueno y lo malo, antes que a negar la existencia del vínculo mismo. Pero si esto no es suficientemente claro en esta parte, en cambio, es más visible que el párrafo de la página 521 está enfáticamente dirigido al plano lógico, desde él cual no puede proyectarse una separación absoluta para las relaciones fácticas ser-deber ser, sin riesgo de poner en cuestión la propia teoría de los sentimientos morales HumEana. Uno de los primeros en resaltar la posibilidad de esta explicación contradictoria de la posición de HuME, siguiendo la crítica de autores intuicionistas, es FRANKENA, en su trabajo de 1939. De acuerdo con él, la interpretación estándar de la tesis de HuME — extendida con descuido, según pensamos desde el nivel lógico al nivel óntico (aunque FRANKENA no hace esta distinción) — «subvertiría» las definiciones «naturalistas» de vicio y virtud, bien y mal, que ofrece HuME ${ }^{16}$. La opinión de MACINTYRE es semejante: «si la interpretación corriente de HumE sobre "ser" y "deber ser" es correcta — dice-, entonces la primer violación de la ley de Hume fue cometida por HumE» ${ }^{17}$.

De acuerdo con estos esclarecimientos la teoría de HumE podría ser resumida, sin distorsiones graves, así:

a) Sólo son posibles afirmaciones de razón sobre hechos externos (que él llama «relaciones»).

b) Las pasiones, como los sentimientos, no son «relaciones» externas, por lo tanto no son susceptibles de afirmaciones de razón, o de demostraciones de verdad o falsedad (veremos más adelante que, desde la posición de Hume, esto no afecta la posibilidad de avanzar hacia principios morales).

c) Afirmaciones de «debe» no pueden derivarse («deducirse») lógicamente de proposiciones de «es» (regla de no derivabilidad formal).

d) El debe se basa, o es expresión, de sentimientos y emociones. En relación con la regla de la no derivabilidad lógica, esta tesis no resulta contradictoria en tanto ambas tienen diferente objeto: la primera se ocupa de las posibilidades de inferencia lógica de las proposiciones de deber ser, y la segunda de las condiciones de existencia de la moral. En cambio, si las expresiones del citado párrafo de Hume se asumen como equivalentes a una inconmunicablidad absoluta (lógica y material) entre «ser» y «deber ser», se plantea de inmediato una evidente contradicción con la teoría moral del autor como ya se ha advertido. Siendo las pasiones base de la moralidad - y aun en el extremo de suponer que sean completamente caprichosas y aleatorias- estas constituyen después de todo un es, es decir, existen; por tanto ¿cómo podrían originar un debe en las condiciones de una «guillotina» pensada de ese modo?

Las posibilidades para sacar a HumE del problema serían tres:

d.1. Mantener que la tesis HumEana se refiere sólo a la conexión lógico-deducti-

${ }^{16}$ Frankena, 1939: «The Naturalistic Fallacy», en Mind, New Series, vol. 48, n. ${ }^{\circ} 192$ (octubre), p. 466.

${ }^{17}$ MaCINTYRe, 1959: 452. 
va (regla de no derivabilidad formal), lo cual no equivale a decir que las circunstancias morales no puedan descansar en algún tipo de hechos como las pasiones. En este caso se podría buscar fundamentar la conexión ser-deber ser por otros medios no lógico-deductivos; inductivos por ejemplo, a la manera de lo postulado por MACINTYRE (véase nota 8). Esta posición se muestra bastante persuasiva, y parece corresponder con la coherencia global de la teoría moral de Hume, aunque pueda ser dudoso que Hume perciba con suficiente claridad las diferentes dimensiones implicadas en el problema que afronta.

d.2. Sostener la tesis de la incomunicabilidad absoluta en Hume, pero negando que en él las pasiones constituyan hechos, sino manifestaciones de un «debe» no describible y no teorizable; algo así como un simple sonido de la garganta, un capricho contingente o un a priori no existencial, o tan trivial que difícilmente podría intentar fundamentarse. Sin embargo, se ha visto que Hume atribuye relaciones demostrables a la materia, así como a las acciones, pasiones y voliciones (515); por tanto la existencia real de las pasiones no puede ser negada, de donde devendría el misterio de cómo entonces las pasiones pueden originar afirmaciones morales en condiciones de la tesis de incomunicabilidad.

d.3. Defender la tesis de la incomunicabilidad absoluta pero aceptando que eso no elimina el que HumE pudiera haber incurrido ocasionalmente en la inconsecuencia naturalista que allí cuestionaría ${ }^{18}$. Sin embargo, es difícil conceder que el verdadero HumE puede ser encontrado en un párrafo de 22 líneas, y no en las restantes quinientas páginas que explican su teoría.

Por consiguiente, lo más verosímil es pensar que HuME tiene claridad sobre la tesis de la no derivabilidad lógica, así como la tiene respecto a su teoría de los sentimientos morales. En cambio, parece indiferente a las relaciones entre ambas. En apariencia no se da cuenta del posible conflicto en que pueden desembocar; sin embargo, otra explicación creíble es que, guiado por el buen sentido común del que se sirve con frecuencia en su razonamiento, no se muestra interesado en esclarecer ello porque intuitivamente percibe que no hay contradicción alguna entre mantener lo uno y lo otro, según se verá más adelante. La tesis de no derivabilidad no lleva a Hume a trazar una incomunicabilidad absoluta entre ser y deber ser.

Una pregunta pertinente en este punto es si de la regla de no derivabilidad infiere HuME la imposibilidad de hacer aserciones morales independientes, aunque no fuesen basadas en hechos, sobre supuestos puramente deontológicos o prescriptivistas, por ejemplo. ¿O es que la regla de la no derivabilidad implica también que el entendimiento humano sólo tiene posibilidad de establecer proposiciones de es estando vedado, en cambio, de poder hacer algún juicio de deber ser sobre bases propias? Si Hume hubiese negado la posibilidad de juicios morales, o que estos carecen de sentido, tendríamos que emparentarlo de algún modo con las creencias del positivismo lógico; pero esto no se implica en la exposición humeana. Ciertamente, cuando en el Treatise afirma que la moralidad no es demostrable, parece implicar la imposibilidad de hacer alguna afirmación descriptiva acerca de ésta; sin embargo esto es sutilmente distinto a postular la im-

${ }^{18}$ PORTER, por ejemplo, cree que HumE es «sincero» en la tesis de la no derivabilidad lógica, pero ello no evita que haya ocasionalmente caído en errores en su teoría. PORTER, 1968: Deity and Morality London: Georg Allen and Unwin, Ltd, p. 12. 
posibilidad de los juicios morales o que estos carezcan de sentido. Por lo demás su escepticismo intelectual respecto de las pasiones parece atenuarse significativamente en las Enquiries. En prueba de ello se puede citar este ilustrativo párrafo:

El único objeto del razonamiento es descubrir las circunstancias de ambos lados (lo que es valioso y lo que es condenable, nota del autor) que son comunes a estas cualidades; observar las particularidades estimables en un lado, y las condenables en la otra; $y$ por tanto alcanzar los fundamentos de la ética, y encontrar esos principios universales de los cuales toda la censura o aprobación es ultimadamente derivada. Como esta es una cuestión de hechos, no de ciencias abstractas, únicamente podemos esperar tener éxito siguiendo el método experimental, deduciendo (sic) máximas generales de la comparación de instancias particulares (énfasis añadido) ${ }^{19}$.

En otras palabras, HumE no asume que haya impedimento para que a partir de las pasiones se puedan derivar aserciones éticas del tipo de «principios universales». Lo que cuestiona es el método de los filósofos en boga, de establecer primero un «principio general abstracto» del cual se obtienen luego las derivaciones, en vez de favorecer un método «experimental» - léase inductivo- para llegar a esos principios. En el contexto de su teoría hay que entender luego que esta «comparación» es posible sobre la base de pasiones y sentimientos reales. La conducta moral no puede derivar de ideas puras; sin embargo esto no significa que los sentimientos no puedan ser inductivamente «abreviados» para dar origen a algún tipo de principios éticos. Se plantea entonces el problema de si cuando HuME afirma que se puede «encontrar esos principios universales» siguiendo el método experimental, no está diciendo con ello —contra sus creencias iniciales- que tales principios son demostrables. HumE no se preocupa de aclarar estas diferencias, las que pueden quedar en la incertidumbre o como indicio de las imperfecciones verbales en su filosofía; pero esas imperfecciones no llevan a sostener que la posibilidad de juicios morales sea negada por él, sino al contrario.

Sin embargo, el problema principal que subyace a sus preocupaciones, en especial en el Treatise, parece ser cómo la moral motiva, no tanto cómo son posibles las aserciones morales, ni cuáles son los contenidos de la moral. Cree que las conductas morales ocurren porque tenemos sentimientos; no porque tengamos ideas; por tanto la conducta moral no puede derivar de ideas puras. Pero de por sí esto no significa que los sentimientos no puedan ser expresados en ideas, ni que esas ideas una vez afirmadas no puedan pensarse en alguna forma lógica. Si de la insistencia de HuME en que sólo las pasiones motivan, que la moral está basada en pasiones, y que la moral no es demostrable, alguien quisiera concluir que para él las aserciones morales no son posibles, sin duda estaría yendo más allá de lo que su teoría sugiere. Mayores pruebas de que HumE acepta la posibilidad de hacer aserciones morales, o de estatuir «principios» éticos, se hallan no sólo en su tratamiento de las «afecciones morales» en las partes II y III del libro III del Treatise; sino en particular en sus Enquiries de 1777 el cual desde su título reza como «Investiga-

${ }^{19}$ «The only object of reasoning is to discover the circumstances on both sides (estimables o condenables), which are common to these qualities; to observe that particular in which the estimable qualities agree on the one hand, and the blameable on the other; and thence to reach the foundation of ethics, and find those universal principles, from which all censure or approbation is ultimately derived. As this is a question of fact, not of abstract science, we can only expect success, by following the experimental method, and deducing general maxims from a comparison of particular instances...» HuME, 1978: 174.

${ }^{20}$ HuME, 1978 [1777]. 
ciones sobre el Entendimiento Humano y los Principios de la Moral» ${ }^{20}$ (énfasis añadido).

Con base en todo esto se está en posibilidad de confirmar que la regla de no derivabilidad no elimina el naturalismo de HumE, porque entonces toda su teoría moral se cae. El naturalismo de HumE es más o menos reconocido por la mayoría de autores que se ocupan de él (al lado de las calificaciones de escepticismo, empirismo que su obra también recibe). KEMP recuerda que esto surge claramente desde la propia página del título del Treatise, que su autor describe como «Un intento de introducir el método experimental de razonamiento en asuntos morales» ${ }^{21}$. Esta orientación se mantiene en las Enquiries, conforme se ha visto del párrafo citado antes. Más adelante añade en ese texto: «Los hombres están ahora curados de su pasión por las hipótesis y sistemas en filosofía natural, y no escucharán sino aquellos argumentos derivados de la experiencia. Es tiempo de intentar una reforma en todas las disquisiciones morales, y rechazar todo sistema de ética, aunque sutil e ingenioso, que no sea fundado en los hechos y en la observación» (énfasis añadido) ${ }^{22}$. Más allá del éxito o no de sus teorías el naturalismo moral de Hume resulta harto evidente.

Cabe ahora preguntarse, desde un punto de vista teórico, si a pesar de HumE la regla de no derivabilidad formal no pone una valla definitiva a la posibilidad de una fundamentación naturalista de la moral. Hasta donde se lleva dicho, HumE no se ocupa de este conflicto; en todo caso, su teoría moral podría usarse como una prueba de que una fundamentación naturalista es posible, o cuando menos vale la pena intentarlo. ¿De dónde viene entonces la creencia de que la «guillotina» de HumE impide que la naturaleza cuente para el discurso moral? Esto nos lleva inevitablemente a las puertas de MOORE.

\section{2. ¿HAY UNA «FALACIA NATURALISTA»?}

La expresión «falacia naturalista» no aparece en los trabajos de HumE y viene acuñada por G. E. MOORE, en diferentes partes de su libro Principia Ethica de 1903. Es significativo que MOORE no recurre a HuME en la citada obra, cuando se propone explicar la llamada falacia ${ }^{23}$, lo que hace dudar de que ambos autores se estén ocupando de lo mismo, o de que estén afirmando exactamente la misma conclusión ${ }^{24}$ —aunque pueda haber algún tipo de analogía en sus planteamientos.

${ }^{21}$ Kemp, 1970: Ethical Naturalism: Hobbes and Hume, MacMillan Press, p. 29. Puede verse también MounCE, 1999: HumE's Naturalism, Routledge, pp. 77 y ss.; HARRISOn, 1976: HumE's Moral Epistemology, Oxford: Clarendon Press, p. 125.

${ }^{22}$ «Men are now cured of their passion for bypotheses and systems in natural philosophy, and will bearken to no arguments but those which are derived from experience. It is full time they should attempt a like reformation in al moral disquisitions; and reject every system of ethics, bowever subtle or ingenious, which is not founded on fact and observation». HuME, 1978: 175.

${ }^{23}$ Moore se refiere a diferentes autores, Hegel, Kant, Sigwick, Hobbes, Leibniz, Spencer, Mill, entre otros; sin embargo Hume no es citado como antecedente en ningún lado. Véase Moore, 1971 [1903]: Principia Ethica, Cambridge at the University Press. No han faltado autores, sin embargo, que identifican rápidamente la expresión de MOORE con la tesis de la no derivabilidad lógico-deductiva del recorrido párrafo de HuME; Porter y Hare entre ellos. Véase Porter, 1968: 11; Baldwin, 1990: G. E. Moore, Routledge, p. 90.

${ }^{24}$ Véase PORTER, 1968: 13; BALDWIN, 1990: 90. 
La regla de no derivabilidad, en Hume, según se dijo, sólo expresa que de afirmaciones de ser no pueden obtenerse deductivamente afirmaciones de deber ser; de donde no se sigue por HuME que los juicios morales sean imposibles sobre bases naturales. Ciertas expresiones suyas sobre la naturaleza infinita de las pasiones y de los sentimientos, pueden echar dudas sobre la posibilidad de que las emociones morales sean describibles, pero no sobre su creencia en que la moral descansa en sentimientos ni en la posibilidad de alguna clase de naturalismo como base de la moralidad.

MOORE, por su lado trabaja en otra dirección. Él cree que lo bueno (goodness), o lo correcto (rightness), como objeto de la moral no se identifica con las propiedades naturales de lo «placentero», lo normal, lo que corresponde a la voluntad de Dios, etc. ${ }^{25}$ «Lo bueno», no existe como propiedad real de los objetos concretos; sino quizás más bien como una propiedad abstracta a la cual se accede por intuición ${ }^{26}$. Sostener lo contrario, sería lo que llama una «falacia naturalista» ${ }^{27}$. MOORE cree que las propiedades buenas que atribuimos a los objetos o situaciones que nos producen placer, no equivalen a «lo bueno» como categoría de la ética. Lo bueno constituye el peculiar predicado en referencia al cual se define la ética, y este predicado es indefinible y no analizable ${ }^{28}$.

NOWELL-SMITH, profundo conocedor del pensamiento de MoORE, en tanto seguidor del mismo, reconstruye el razonamiento que el autor de Principia sigue para llegar a este resultado, en términos que parafraseamos a continuación:

a) Las palabras expresan objetos o ideas, las cuales son simples o complejas.

b) Definir una palabra compleja equivale a descomponerla en sus partes. Por ejemplo una quimera es un animal con cabeza y cuerpo de león, una cabeza de cabra en su espalda y una serpiente en lugar de cola.

c) Una palabra simple no puede definirse porque no puede descomponerse; por ejemplo la palabra «amarillo». Lo mismo ocurre con la palabra «bueno».

d) Las ideas simples no son «naturales» ni «no naturales», en el sentido de que no pueden conocerse ni por los datos de los sentidos ni por introspección ${ }^{29}$.

Por lo tanto la palabra «bueno» no sería «natural» ni «no natural». Existen ciertas

${ }^{25}$ Novell-Smith, 1954: Ethics, Penguin Books, p. 33.

${ }^{26}$ Idem.

${ }^{27}$ Véase Moore, 1971:38-39. En diferentes partes de su texto clave trata de explicarla, una de ellas es la siguiente:

«And it is a fact, that Ethics aims at discovery what are those other properties belonging to all things which are good. But far too many philosophers have thought that when they named those other properties they were actually defining good, that these properties in fact were simply not other, but absolutely and entirely the same with goodness. This view I propose to call the "naturalistic fallacy" and of it I shall now endeavour to dispose». MoORE, 1971: 10. En otro lado se encuentran expresiones adicionales que ayudan a aclarar su punto de vista. Caracterizando el método «naturalista», que MOORE encuentra inconsistente con las propiedades de la Ética, escribe: «This Method consists in substituting for "good" some one property of a natural object or a collection of natural objects; and thus replacing Ethics by some one of the natural sciences». MOORE, 1971: 40.

${ }^{28}$ MOORE, 1971:3.

${ }^{29}$ Novell-Smith, 1954:33. Obsérvese que $d$ ) no se sigue de las afirmaciones precedentes, y es introducida como afirmación dogmática.

${ }^{30}$ Es importante anotar, a propósito, que de acuerdo con BALDWIN, las enunciaciones de MOORE no son del todo coincidentes en los diferentes párrafos de su obra, y la falacia parece implicar tres aserciones que MoORE no termina de aclarar: $a$ ) la negación de que «lo bueno» es indefinible, $b$ ) la afirmación de que «lo bueno» reside en un objeto diferente, o que corresponde con una noción diferente $c$ ) la negación de que lo bueno es no-natural. BALDWIN, 1990: 70. 
propiedades buenas en los objetos, pero «lo bueno» no puede ser identificado con esas propiedades. Esta es la versión de la falacia, que a nuestro modo de ver debe entenderse como la dominante ${ }^{30}$. Las pruebas que MOORE aduce para sostener ello pueden resumirse en tres:

a) La que llama prueba de la «existencia» en el tiempo: las propiedades buenas de los objetos, por más numerosos que sean, son predicados de los objetos y no pueden permanecer si se suprimen ellos. Pero esto no ocurre con lo bueno ${ }^{31}$ que presuntamente permanecería en el tiempo.

b) En otro lado postula que los principios fundamentales de la Ética son proposiciones sintéticas no analizables, como en el ejemplo del color amarillo ${ }^{32}$.

c) Finalmente cuenta el argumento conocido como de la «pregunta abierta»: alguien puede desear algo que considera bueno - por ejemplo, lo placentero es bueno- pero siempre será posible preguntarse de ello ¿Pero es lo placentero bueno en sí mismo? ${ }^{33}$.

Lo primero a observar aquí es lo dudoso del argumento de la existencia. ¿Sobre qué base se puede creer que suprimidos los objetos con propiedades buenas subsistiría la idea de «lo bueno»? Si suponemos que ninguna persona del planeta hubiese tenido nunca alguna experiencia de los objetos y situaciones buenas, chabría siquiera surgido la posibilidad de la idea o el concepto de «lo bueno»? Este resulta, evidentemente, un supuesto ideal acerca del cual no pueden aducirse pruebas, ni a favor ni en contra.

En segundo lugar, se puede dudar de que «lo bueno» sea una propiedad simple como el color amarillo, imposible de definir y cuya existencia sin embargo podría intuirse separada de las cosas que apreciamos buenas. Después de todo el color amarillo por sí mismo no existe - salvo como concepto—, y lo que existen son sólo diferentes, muchísimas, sustancias que poseen esa cualidad (en infinitos matices por supuesto); el amarillo como tal es sólo una propiedad inseparable de ellas. ¿Está acaso MOORE razonando como un realista medieval y asumiendo que lo bueno es un universal existente por sí mismo y separado de las cosas que lo portan?

Resulta evidente que lo que MOORE cuestiona, en realidad, es el procedimiento psicológico y racional que lleva a formular el concepto de lo bueno a partir de las propiedades de lo bueno que se encuentran en las cosas y situaciones ${ }^{34}$. Tanto así como cuestionar que la noción de color amarillo pueda formularse, a partir de reparar que muchas de las cosas existentes poseen esa cualidad análoga. Bajo este punto de vista nunca sería posible para las llamadas ciencias formular conceptos valorativos como los de «dureza», o «velocidad» o «acidez», por ejemplo (en general no sería posible formular nin-

31 «If they were all -las propiedades de los objetos- taken away, no object would be left, note ven a bare sustance: for they are in themselves substancial and give to the object all the substance that it bas. But this is not so with good». El uso ambiguo que MoORE hace de la palabra «good» dificulta seguirlo en esta parte, pero creemos que la reconstrucción hecha corresponde al sentido de la frase que se cita. MOORE, 1971: 41.

32 MOORE, 1971: 58.

33 MoORe, 1971: parágrafo 13.

34 Observemos que MOORE piensa que la noción de «lo bueno» (Goodness) es «una proposición sintética», emplea esta noción en cierto sentido apriorístico, a la manera de KANT, en lugar de entenderlo como un juicio derivado de varias experiencias. Cfr. SCHroeder, 2006: Wittgenstein, Polity, p. 240. 
gún concepto), porque en la práctica se pueden encontrar cosas más duras o menos duras, más veloces o menos veloces, más ácidas o menos ácidas. Por lo tanto —viene aquí la tercera réplica- enfrentando una situación concreta - como un pan duro en la mesa, un scooter corriendo en la pista, o un sorbo de limonada en la garganta, siempre habrá lugar para «preguntas abiertas» como «ंes ésta la dureza?», «¿es ésta la velocidad en sí misma?», «¿es ésta la acidez?»- Es difícil creer que el procedimiento inherente a la mente humana para construir categorías generalizadoras del entendimiento pueda ser desechado como una falacia ${ }^{35}$.

PORTER ha sugerido que MOORE utiliza la denominación de «falacia» en una forma equivocada ${ }^{36}$; puede aceptarse sin embargo que aquí MoORE esté hablando de «falacia» en un sentido amplio, como un argumento erróneo, y no en el sentido estricto de una falla en los procedimientos deductivos. La mayoría de creyentes en la «falacia naturalista» pensarían en cambio que MOORE se refiere a una falacia lógica semejante a la de Hume, lo cual no surge de MoOrE ${ }^{37}$. Por tanto, a la pregunta qué tiene que ver la una con la otra, la respuesta es más o menos obvia. Se trata de dos problemas diferentes $^{38}$, por el objeto del que se ocupan, por el procedimiento que siguen y por las conclusiones a que arriban ambos autores.

El «ser» implicado en la regla de HumE es una proposición formal no identificable como tal, con las «propiedades buenas» que MOORE reconoce en las cosas; así como el «deber ser» humeano es otra proposición formal que tampoco equivale a «lo bueno» como peculiar predicado de la ética mooreana. Hume se ocupa de un problema lógico-deductivo: la posibilidad de afirmaciones de deber ser a partir de afirmaciones de es; el de MOORE parece más bien un problema gnoseológico de carácter inductivo: la posibilidad de construir conceptos a partir de datos particulares de la experiencia. Si se

35 FRANKENA hace notar, por otro lado, la curiosa manera en que se puso de moda la palabra «falacia», a comienzos del siglo XX, para desacreditar a los adversarios. «Los futuros historiadores del "pensamiento y la expresión” en el siglo XX — dice— no dudarán en registrar con algo de humor el ingenioso truco usado por algunos de los contrincantes filosóficos de comienzos de siglo, de etiquetar los puntos de vista de sus oponentes como "falacias"». FranKENA, 1939: 464.

36 Porter, 1968: 13-14. También Bruening: «Moore and "Is-Ought”», Ethics, vol. 81, n. ${ }^{\circ} 2$ (Jan., 1971), p. 144. De acuerdo con este útimo autor, hacia 1942, MoORE habría aceptado lo inexacto de esa denominación.

37 BRUENING, indica que entre los que vinculan el problema de HuME con el de la falacia naturalista, se hallan el propio SEARLE —intentando refutar a Hume-, SteVEnson, WAdDingot, Murdoch, Novel-Smith, VeAtCH, PrIOR, FLEW y Bruening, «Moore and "Is-Ought"», Ethics, vol. 81, n. ${ }^{\circ}$ 2. (Jan., 1971), p. 147. Otra curiosidad es que los seguidores de MOORE — y no pocos de sus críticos_ parecen haberle dado a la llamada falacia naturalista más atención de la que el propio MOORE le presta luego de la publicación de sus Principia. En efecto algo extraño es que en el siguiente texto importante de MoORE, Ethics, publicado en 1912, el autor no vuelve a ocuparse de la «falacia». Más aún, salvo su trabajo de 1932, The Conception of Intrinsic Value, en el que añade supuestos para una crítica al naturalismo ético. Cfr. BALDWIN, 1990: 67 y 68. En el resto de sus trabajos posteriores la falacia no vuelve a aparecer. BALDWIN cree que es más probable que esto ocurra no porque MOORE sienta que ha dicho todo lo que tenía que decir sobre el tema, sino porque tempranamente se dio cuenta que la tesis de la «falacia naturalista» - la tesis principal en sus Principia_ era altamente confusa y quizás pensó que tales confusiones no se podrían superar. BALDWIN, 1990: 67.

38 La comparación de ambos problemas lleva incluso a BRUENING a concluir que MOORE estaría sosteniendo lo contrario de lo que algunos autores mantienen al postular la imposibilidad de reducir las afirmaciones evaluativas a afirmaciones de hecho: «In conclusion, then, Moore's naturalistic fallacy is not the same thing as the "is-ought" problem. He is not saying that evaluative statements are not factual. Quite the contrary, he seems to speak. in such a way as to deny the distinction between factual statements and evaluative statements as it is made today» BRUENING, 1971: 148. 
viola la regla de Hume tenemos una falacia lógica (discutiblemente una que deba ser llamada «naturalista»). Si se sostiene la posibilidad de construir conceptos -incluido el concepto de «lo bueno» o cualquier otro valorativo- a partir de los datos de la experiencia no se tiene una falacia, sino que el razonamiento se ajusta a uno de los procedimientos del entendimiento humano comúnmente practicados, y reconocidos en las teorías del conocimiento. Por el contrario, si se niega la posibilidad del paso de la experiencia al concepto se llega inevitablemente a algún tipo de escepticismo, y se pone en cuestionamiento todo el sistema de conceptos usados para poder entendernos, aun en medio de las innumerables imperfecciones lingüísticas que puedan constatarse.

De la regla de no derivabilidad, Hume no transita a sostener que lo bueno (las virtudes) no existan, aun cuando sean dependientes de las pasiones; más aún, como se ha visto, no llega a sostener que no puedan emitirse juicios morales («principios») fundados en la experiencia natural ${ }^{39}$. MOORE tampoco niega la existencia de propiedades de lo bueno como propiedad de ciertos objetos; sin embargo niega que se pueda formular un concepto de lo bueno a partir de ellos ${ }^{40}$. A diferencia de la «guillotina» formal de Hume que establece una prohibición deductiva entre juicios de significado diferente, MOORE establece una «guillotina» entre la experiencia (la realidad) y los conceptos.

\section{AUTONOMÍA DE LOS JUICIOS MORALES}

Si de la regla de no derivabilidad Hume hubiese pasado a sostener que los hechos morales no existen, o que las experiencias morales no pueden fundar principios morales, habría incurrido sin duda en una falacia de carácter idealista: el intento de negar existencia a ciertas propiedades valorativas porque no se siguen deductivamente de un razonamiento. Del hecho de que enunciados de deber ser no puedan obtenerse de enunciados es por vía deductiva, no se infiere la inexistencia — ni la existencia- de hechos morales ni la imposibilidad —ni posibilidad — de sustentar la moral en las condiciones naturales. En general, no se infiere nada con carácter de necesidad para las circunstancias fácticas por el hecho incontrovertible de que no hay relaciones lógicas —en el sentido deductivo- entre hechos y enunciados. Las relaciones lógicas se plantean formalmente entre enunciados lingüísticos, el que correspondan o no con circunstancias reales

${ }^{39}$ HumE se pregunta expresamente si esos «principios» se encuentran en la naturaleza o tienen algún otro origen y su respuesta es que la distinción entre vicio y virtud es «natural», si por natural se entiende lo opuesto a los «milagros» (es decir lo no existente) esto es así; si por natural se entiende lo opuesto a lo raro o lo inusual —aun con lo difícil que es fijar los límites entre lo raro y lo frecuente- HumE cree igualmente que los sentimientos morales son naturales. Su duda se mantiene únicamente para el caso de que por naturaleza se entienda lo opuesto a lo artificial, en cuyo caso confiesa no tener una respuesta precisa. Sin embargo aún cuando concluyese en que los sentimientos morales son artificiales en tanto se originan en el hombre, ello tampoco derrotaría su creencia en que la moralidad proviene de la experiencia de la que forman parte los hombres. HuME, 1978: 525-526.

40 «For I do not deny that good is a property of certain natural objects: certain of them, I think, are good; and yet I have said that "good" itself is not a natural property». MOORE, 1971: 41.

${ }^{41}$ Entendemos que por esta razón es que los lógicos distinguen los conceptos de validez y verdad. «Verdad y falsedad — dicen COPI y COHEN — se aplican a afirmaciones acerca del mundo; mientras validez e invalidez se aplican a argumentos en los cuales se hacen inferencias de unas proposiciones a otras». COPI e COHEN, 1998: Introduction to Logic, tenth edition, Prentice Hall, p. 29. 
es otro problema, y el que las circunstancias reales existan por sí mismas y puedan corresponder a la misma o a una lógica diferente a la que se usa, es más indiferente aún ${ }^{41}$. No puede pensarse entonces que el párrafo de HumE constituya negación alguna de las posibilidades de fundar la moral en algún tipo de experiencia natural, ni que tenga algún vínculo con la «falacia naturalista» de MOORE.

Lo que hay que preguntarse luego es si, cuando MOORE, partiendo de la afirmación de que el concepto de lo bueno no puede descomponerse en partes para ser definido - una hipótesis analítica por lo demás controvertible- pasa a concluir que lo bueno como propiedad ética no tiene posibilidad de existencia entre las circunstancias naturales, no está incurriendo precisamente en una falacia idealista del tipo señalado: pretender derivar consecuencias lógicas inevitables para la realidad a partir de un razonamiento que en este caso es menos que formal sino, ciertamente especulativo.

Se puede decir entonces que, mientras los argumentos en pro de la existencia de una tal falacia naturalista se muestran notoriamente débiles, en cambio la tesis de la no derivabilidad deductiva de HuME puede ser razonablemente defendida, incluso con independencia de que el esfuerzo de los lógicos pueda en algún momento probar —o descartar- la posibilidad de identidad entre proposiciones del ser y juicios de deber ser. Siguiendo a PigDEN, propiamente lo que HuME está confirmando en ese párrafo es la vigencia de uno de los dogmas - o principios- de la lógica formal, a saber el de conservatividad de los enunciados lógicos y la exigencia de validez en los razonamientos. Afirmar que de un es no puede derivarse lógico-deductivamente un deber ser, es tan cierto como sostener que no se pueden obtener, por medios lógicos, conclusiones para erizos a partir de premisas no referidas a erizos ${ }^{42}$. De las premisas que todos los hombres son mortales, y SÓCRATES es un hombre, no puede obtenerse lógico-deductivamente que SÓCRATES es invulnerable, porque esta última cualidad no se encuentra en las premisas. Y de la premisa Dios es sublime no puede derivarse por medios deductivos la conclusión debes amar a Dios así como de la premisa Amo a Dios tampoco se infiere que Dios es todopoderoso ${ }^{43}$. Esto, de acuerdo con PIGDEN, expresa justamente la idea de que «en lógica no se puede sacar nada que no haya sido puesto en ella» ${ }^{44}$ : no es posible poner pañuelos en el sombrero y sacar un conejo. Desde este punto de vista, la tesis de HumE se revela como una gran trivialidad, en la medida en que sólo confirma una creencia lógica ampliamente aceptada en el razonamiento humano - se piensa que desde ARISTÓTELES-; aunque sin duda en respuesta a un problema indiscutiblemente genuino para las circunstancias confrontadas por el notable pensador inglés.

Pero el problema más serio implicado en la discusión sobre el párrafo de HumE, a nuestro modo de ver, no reside en cómo se puede o no se puede obtener afirmaciones de deber ser a partir de proposiciones referidas al ser, sino en cual es la necesidad de que haya conexiones lógicas entre estas proposiciones de enunciado diferente ¿Por

\footnotetext{
42 Pigden, en Singer, 1997: 423.

${ }^{43}$ En cambio, como hemos sostenido en otro lado, no hay dificultad para derivar deber ser a partir de enunciados de deber ser, evitando las dificultades del dilema de JORGENSEN; y de la premisa «debes cumplir tus promesas» también puede inferirse que «debes cumplir la promesa que hiciste a María», si concurre el caso que una tal promesa haya sido hecha. SÁNCHEZ, 2004: Argumentación Jurídica, Un Modelo y Varias Discusiones sobre los Problemas del Razonamiento Legal, Lima: Jurista Editores, pp. 189-191.

${ }^{44}$ Pigden, en Singer, 1997: 424.
} 
qué se necesita que las afirmaciones de ser y deber ser tengan que estar lógicamente conectadas? ¿Por qué no es posible plantear cada cual como aserciones independientes? $¿ \mathrm{O}$ por qué no es posible vincularlas a través de otros procedimientos del pensamiento? En apariencia la angustia generada por la confusión de la regla de no derivabilidad con un postulado de incomunicabilidad absoluta —-multiplicada por el efecto retórico de la expresión «falacia naturalista»-, descansa en la creencia tácita de que al no poder las afirmaciones de deber ser derivarse de proposiciones del ser, no podrían derivarse de nada. Se implica con ello, por tanto, que tampoco habría legitimidad para establecerlas como proposiciones autónomas. Esta creencia resulta sin embargo injustificada. Si para aceptar una aserción lingüística ésta necesita derivarse lógico-deductivamente de algo, entonces tampoco habría legitimidad para establecer aserciones de es, porque estas proposiciones tampoco se derivan lógicamente (en el sentido deductivo) de algo.

Afirmar que «el sol brilla» no se deduce lógico-deductivamente de nada, sino de la circunstancia fáctica de que ese hecho se está produciendo ante mis sentidos ${ }^{45}$. En sus orígenes últimos las afirmaciones de es no se siguen de algo por procedimientos deductivos. Son propiamente estipulaciones lingüísticas respecto a la información recibida del mundo por canales que no son del caso discutir ahora; pero no se siguen deductivamente de éste. La razón para ello es la que de los hechos no se sigue el lenguaje; se sigue el sonido de la lengua y el fenómeno de la mente, pero no las afirmaciones lingüísticas del pensamiento - ulteriormente verbalizadas - las cuales son una representación subjetiva autónoma, y no un mero reflejo del mundo exterior. Las proposiciones no se siguen lógico-deductivamente de las cosas, son afirmaciones humanas, que sin embargo corresponden - o buscan corresponder - semánticamente con la realidad. Y las propiedades deductivas se predican de los sistemas de lenguaje, válidas - o no- por su correspondencia lingüística interna; pero verdaderas - o no- por su correspondencia con las condiciones que puedan homologarse en la realidad. De las palabras sólo se siguen lógicamente palabras, así como de los hechos los hechos; cada cual en su propia «lógica» (lo mismo en sus interacciones). Sin embargo las palabras son nuestro vehículo para expresar las relaciones con el referente y pueden hacerlo en diferentes formas, por lo menos en dos: afirmando que algo es, o afirmando que algo tiene alguna clase de valor (suscita un sentimiento positivo o negativo para el sujeto) y por lo tanto es valioso o disvalioso promoverlo. Entendemos que a partir de esta distinción básica se ha construido todo el aparato de conocimientos descriptivos llamado «ciencia» así como el mundo tecnológico y por supuesto el mundo moral-normativo en el que nuestra existencia tiene sentido.

La posibilidad real —llámese física, psicológica o intelectual— de formular juicios de deber ser no puede discutirse, desde que esto es algo que los colectivos humanos vienen haciendo seguramente desde la aparición del pensamiento; el único problema es si se puede racionalmente aceptar la enunciación de los mismos como premisas de la sabiduría y actuación humanas, lo que aquí estamos denominando perentoriamente como el problema de la legitimidad para estatuir juicios morales autónomos en su formulación lingüística. Pero si lo que determina la legitimidad de un juicio es la cualidad de

${ }^{45}$ Esa verdad la puede el sujeto felizmente expresar en lenguaje pero mal podría, por supuesto, creer que esa verdad proviene de las deducciones del lenguaje y no de la realidad. 
provenir de una inferencia deductiva, entonces, si no hay legitimidad deductiva para estatuir aserciones de deber ser, tampoco la habría para hacerlo con proposiciones del ser, y al contrario. Por tanto, tan legítimo es establecer premisas autónomas de es, como premisas autónomas de deber ser en la medida en que ambos expresan diferentes propiedades de la experiencia humana. El establecimiento de estos dos tipos de premisas ha de verse entonces como actos lingüísticos análogos y autónomos suscitados por la realidad, lo que no elimina, por cierto, que unos puedan sustantivamente servir de base para los otros a partir del intercambio de la información que portan. Entendemos que en esto reside, precisamente, la autonomía lógica y semántica de la moral, lo cual no conduce a postular inevitablemente la autonomía ontológica de la misma, ni su existencia en un mundo ajeno al de las circunstancias existentes, ni la imposibilidad de una fundamentación naturalista de la misma ${ }^{46}$.

\section{RESUMIENDO EL RECORRIDO}

La revisión emprendida de las postulaciones de HumE principalmente en el Treati$s e$ y la crítica de la filosofía del profesor MOORE, lleva a reparar que hay en la teoría de HumE numerosos e importantes aspectos implicados, que el propio HumE no termina de diferenciar, y que pueden estar en el origen de las pretensiones anti-naturalistas que a veces tratan de inferirse de su obra. HumE se ocupa al menos de los siguientes problemas:

a) ¿Pueden las ideas producir sentimientos? Para lo cual su respuesta es completamente negativa.

b) ¿Pueden las ideas producir acciones morales? También en esto es definitivo, aunque admite que bajo ciertas condiciones las ideas podrían «indirectamente» orientar las acciones morales.

c) ¿Se basa la moral en ideas abstractas o en sentimientos? Y definitivamente lo que HumE cree es que la moral depende de sentimientos.

d) ¿Pueden los sentimientos morales ser expresados en ideas? HuME no es suficientemente explícito sobre esto, pero procede sin duda en sus explicaciones sobre el supuesto de que la formación de principios morales es posible.

e) ¿Pueden las ideas morales (expresadas en proposiciones de deber ser), basadas en sentimientos, inferirse lógicamente de ideas (proposiciones) sobre el ser? HuME respondería que no, aunque la tesis no se postula por él en tono afirmativo, sino más bien irónico, como un cuestionamiento de lo que vendrían haciendo los filósofos tradicionales.

f) ¿Pueden las ideas morales basarse en principios abstractos o deben encontrarse estos por medio de la experiencia? HuME es explícito en negar lo primero, pero más implícito en sostener lo segundo. En el final no hay duda que reconocería, en el contexto de su teoría moral, que las directrices morales provienen de la experiencia.

Lo que es importante anotar aquí es que la respuesta a la pregunta $e$ ) no tiene implicancias para el resto. Esta afirmación, entendida como una verdad formal, convive

\footnotetext{
46 Pigden, en Singer, 1997: 426-427.

47 Pigden, en Singer, 1997: 427.
} 
pacíficamente con el naturalismo moral prevalente en la filosofía del pensador inglés. Como afirma PIGDEN ${ }^{47}$, la posibilidad de un naturalismo moral, no resulta afectada para nada por el razonamiento de HUME, y desde luego menos aún por las explicaciones de MOORE. El mito de la falacia puede considerarse saldado de este modo. Subsiste en cambio la cuestión de cuáles podrían ser ese tipo de hechos naturales sobre los cuales existe y puede fundamentarse la moral, si ello es posible.

Cualquiera sea el camino que pueda seguirse desde aquí (en el que desde luego hay importantes autores trabajando), lo que por ahora vale la pena anotar es que el breve recorrido intentado nos lleva a pensar que, cuando los filósofos creen que la moral no puede ser derivada de las circunstancias de la experiencia humana y de la vida en común, sino de alguna región lejana a la que sólo los filósofos tendrían acceso, ellos y no el sentido común, parecen estar equivocados. 